\title{
G. Firth, R. Berry and C. Irvine: Understanding Intensive Interaction: Context and Concepts for Professionals and Families
}

\author{
Jessica Kingsley Publishers, London, 2010, 240 pp., ISBN 978-1-84310-982-2, \\ \$32.95; $£ 17.99$ (paper)
}

\author{
Ken Aitken
}

Published online: 20 February 2011

(C) Springer Science+Business Media, LLC 2011

Intensive Interaction is described as an approach to building a framework for communication with others who are in 'the early stages of communicative development'. It has been used most widely with individuals who have both ASD and global learning disability. The approach was developed by Phoebe Caldwell, a British therapist who has been using it with individuals with severe learning disabilities for over 35 years. It is more pragmatic than theoretical in its origins but draws for its theoretical rationale on the clinical and research literature on early social interaction (see, for review: Trevarthen and Aitken 2001).

The focus of Intensive Interaction is on improving communication with and the quality of life of those whose social deficits make normal patterns of communication difficult to establish and sustain. The aim is not to achieve gains in tangible outcome measures of ADL, autistic symptomology or cognition, but rather to improve the enjoyment through social interaction of individuals whose social lives are often limited and self-isolating. There is currently a paucity of systematic methods for assessing and objectifying these aspects of everyday social functioning and demonstrating the effects of approaches such as this.

This book is slightly more academic in focus than most of the literature on Intensive Interaction that has been published to date. It provides a review of the practical and theoretical bases that underpin the approach.

For those who want to acquire more of a 'hands-on feel' for this approach and what is entailed in its application,

K. Aitken $(\bowtie)$

LD-CAMHS Service, Glasgow, and Hillside,

Aberdour, Fife KY3 ORH, UK

e-mail: drken.aitken@btinternet.com
I would recommend reading Firth and Barber (2011) and watching a recent DVD of use of Intensive Interaction in children with ASD (Caldwell et al. 2010). These could usefully be read and watched in tandem with the present volume. There is also a website: http://www.intensiveinteraction.co.uk that provides links to a variety of further information and resources.

This is a helpful little introduction to an approach that provides a way to enrich the lives of many individuals with ASD and severe learning difficulties through making their communication with others more enjoyable. It addresses an important and neglected aspect of the everyday lives of many with ASD.

It has to be said that there needs to be a stronger evidence-base for Intensive Interaction, but the approach highlights aspects of social functioning which are often either implicit in or ignored by other approaches. Currently there are few alternatives for which there is better evidence and this is a critical aspect of functioning which can affect engagement, learning and psychosocial development.

\section{References}

Caldwell, P., Hoghton, M., \& Mytton, P. (2010). Autism and intensive interaction: Using body language to reach children on the autistic spectrum. London: Jessica Kingsley Publishers. DVD (PAL and BTSC formatting) +28 pp. booklet, ISBN 978184905 088 3, \$39.95 US; £19.99 UK.

Firth, G., \& Barber M. (2011). Using intensive interaction with a person with a social or communicative impairment. London: Jessica Kingsley Publishers. 2010, ISBN 978184905109 5, \$21.95. £12.99 (paper).

Trevarthen, C., \& Aitken, K. J. (2001). Infant intersubjectivity: Research, theory, and clinical applications. Annual research review. Journal of Child Psychology and Psychiatry, 42(1), $3-48$. 